\title{
Turbulent Flow and Heat Transfer in Circular Couette Flows in Concentric Annulus
}

\author{
SHUICHI TORII ${ }^{\mathrm{a}, *}$ and WEN-JEI YANG ${ }^{\mathrm{b}}$ \\ ${ }^{a}$ Department of Mechanical Engineering, Kagoshima University, 1-21-40 Korimoto, Kagoshima 890, Japan; ${ }^{\mathrm{b}}$ Department of \\ Mechanical Engineering and Applied Mechanics, University of Michigan, Ann Arbor, MI 48109, USA
}

(Received in final form 5 September 1996)

\begin{abstract}
A numerical study is performed to investigate heat transfer and fluid flow in the hydrodynamically and thermally fully-developed region of an annulus, consisting of a heated rotating inner cylinder and a stationary insulated outer cylinder. Emphasis is placed on the effect of rotation of an inner core on the flow structure and the thermal field. A Reynolds stress turbulence model is employed to determine three normal components of the Reynolds stress and its off-diagonal one. The turbulent heat flux is expressed by Boussinesq approximation in which the eddy diffusivity for heat is given as functions of the temperature variance $\bar{t}^{2}$ and the dissipation rate of temperate fluctuations $\varepsilon_{\mathbf{t}}$. The governing boundarylayer equations are discretized by means of a control volume finite-difference technique and numerically solved using the marching procedure. An inner core rotation causes an amplification of the three normal components of the Reynolds stress over the whole cross section, resulting in a substantial enhancement in the Nusselt number.
\end{abstract}

Keywords: Circular Couette flow, Reynolds stress model, Taylor number, Two-equation heat transfer model

\section{INTRODUCTION}

The convective heat transfer in turbulent swirling flows is often encountered in chemical and mechanical mixing and separation devices, electrical and turbo-machinery, combustion chambers, pollution control devices, swirl nozzles, rocketry, and fusion reactors. In these flow fields, the heat transport phenomena in connection with the flow and the turbulence properties are substantially influenced by the centrifugal force induced by the swirl. In other words, the turbulent transfer of heat and momentum is suppressed or promoted by the interaction between turbulence and centrifugal force associated with the swirl.

Murakami and Kikuyama (1980) measured the velocity profile and hydraulic loss in a hydrodynamically fully-developed flow region of a rotating pipe. It was disclosed that both turbulence and hydraulic loss were remarkably reduced due to pipe

* Corresponding author. Tel.: 099-285-8245. Fax: 099-285-8246. E-mail: torii@mech.Kagashimau.ac.jp. 
rotation and that streamwise velocity profile gradually deformed into a parabolic form with an increase in its speed. Kikuyama et al. (1983) analyzed the variation of streamwise velocity profiles using a modified mixing length theory proposed by Bradshaw (1969). A combined experimental and theoretical study was performed by Hirai and Takagi (1988) using the Reynolds stress model to determine the effects of pipe rotation on fluid flow and heat transfer in a thermally and hydrodynamically fully developed flow region. It was found that an increase in the rotation rate resulted in a decrease in heat transfer performance with the Nusselt number asymptotically approaching that of a laminar pipe flow. Fluid flow and heat transfer characteristics in the thermally and hydrodynamically developing and fully-developed regions of an axially rotating pipe were investigated by Torii and Yang $(1995 \mathrm{a}, \mathrm{b})$ using the existing $k-\varepsilon$ turbulence models in which they are modified to include the swirling effect.

On the contrary, an effect of promoting the turbulent transport of heat and momentum by the centrifugal force occurs in a concentric annulus with an inner cylinder rotating around the axis, in which Taylor vortices appear (Kuzay and Scott, 1975; 1976). Such swirl flow is referred to as circular Couette flow, which implies a flow with one surface rotating and the other stationary (or both surfaces rotating in the same direction at different angular velocities). Hirai et al. (1987) conducted an experimental study on an effect of inner core rotation on turbulent transport of momentum by using a two-color laser Doppler velocimeter. It was disclosed that the Reynolds stresses increase due to the swirl. Torii and Yang (1994) analyzed heat transfer mechanism in annuli with an inner core rotation by means of several different two-equation $k-\varepsilon$ turbulence models. It was found that (i) in the entrance region, the axial rotation of the inner cylinder induces a thermal development and causes an increase in both the Nusselt number and the turbulent kinetic energy in the inner cylinder wall region, and (ii) in the fullydeveloped region, an increase in the Taylor number causes an amplification of the turbulent kinetic energy over the whole cross section, resulting in a substantial enhancement in the Nusselt number.

A $k-\varepsilon$ model, which is one of the two-equation models of turbulence, is popular in computational analyses of turbulent flow. However, in the case of an annular duct flow, the importance of taking the effect of the term, $-\overline{u v} \neq \nu_{\mathrm{t}} \partial U / \partial r$, into account is recognized. This is because the time-averaged local shear stress, $-\overline{u v}$, does not go to zero at the radial location where the time-averaged streamwise velocity has its maximum value, i.e. a radial gradient of zero (Rehme, 1974). Furthermore, since the twoequation $k-\varepsilon$ model basically assumes isotropic turbulence structure, it cannot precisely reproduce the anisotropy of turbulence caused by the inner core rotation. In order to obtain the detailed information pertinent to the flow structures, it is necessary to employ the higher order closure model, i.e. a Reynolds stress turbulence model.

Throughout the numerical simulations for the above turbulent heat transport problems in the swirling flows, the turbulent heat flux in the energy equation is modeled by using the classical Boussinesq approximation. The unknown turbulent thermal diffusivity $\alpha_{\mathrm{t}}$ is obtained from the definition of the known turbulent viscosity $\nu_{\mathrm{t}}$ and the turbulent Prandtl number $\operatorname{Pr}_{\mathrm{t}}$ as $\alpha_{\mathrm{t}}=\nu_{\mathrm{t}} / \operatorname{Pr}_{\mathrm{t}}$. In this formulation, an analogy between eddy diffusivities of momentum and heat is implicitly assumed. However, shear flow measurements (Hishida et al., 1986) and direct simulation data (Kasagi et al., 1992) reveal that its analogy, as represented by the turbulent Prandtl number, cannot adequately reflect the physical phenomenon of heat transport and there are no universal values of turbulent Prandtl number even in simple flows. If the above turbulent Prandtl number assumption is employed to determine the turbulent thermal diffusivity in annuli, it yields negative along the radial direction. This is because the turbulent viscosity, $\nu_{\mathrm{t}}$, becomes negative in the radial region between velocity gradient of zero and Reynolds stress of zero, as mentioned previously. In order to solve this problem and to obtain detailed information on 
the heat transport phenomena, two-equation model for thermal field and turbulent heat flux equation model are considered to be employed.

The heat flux equation model ought to be more universal, at least in principle. This model, however, is still in intensive development and is little used for practical applications (for example, Lai and So, 1990). The results are not as satisfactory as initially expected, mainly due to a few unreasonable hypotheses in the model (Nagano and Tagawa, 1988). Thus, the turbulent heat flux model should wait until the Reynolds stress models are tested and well developed, preferably with the near-wall modeling, since the major source of error in heat transfer predictions is that in calculating the velocity field (Kasagi and Myong, 1989).

This paper treats the thermal transport phenomena in a concentric annulus, in which a slightly heated inner core rotates around the axis and an insulated outer cylinder is held stationary. In order to shed light on the mechanism of the transport phenomena, the Reynolds stress turbulence model proposed by Launder and Shima (1989) is employed, because this model is able to reproduce the inherent anisotropy in the near-wall region of isothermal flows. The turbulent thermal diffusivity $\alpha_{\mathrm{t}}$ is determined using the two-equation model for heat transport proposed by Yousseff et al. (1992). Emphasis is placed on the mechanism of an augmentation of heat transfer performance due to the inner core rotation.

\section{THEORETICAL ANALYSIS}

\section{Governing Equations}

Consider a steady turbulent flow through a concentric annulus consisting of the insulated stationary outer cylinder and the slightly heated inner cylinder rotating around the axis, in which the boundary layer is developing both thermally and hydrodynamically. The physical configuration and the cylindrical coordinate system are shown in Fig. 1. Some approximations are deduced that: (i) viscous heating is negligible; (ii) the axial conduction term in the energy equation is neglected for $\mathrm{Pe}>1$; and (iii) the viscous dissipation term in the energy equation is neglected. An order-of-magnitude analysis indicates all second-derivative terms to be negligible in the streamwise and tangential directions. The simplified governing equations read as follows:

Continuity equation

$$
\frac{\partial U}{\partial x}+\frac{\partial V}{\partial r}+\frac{V}{r}=0
$$

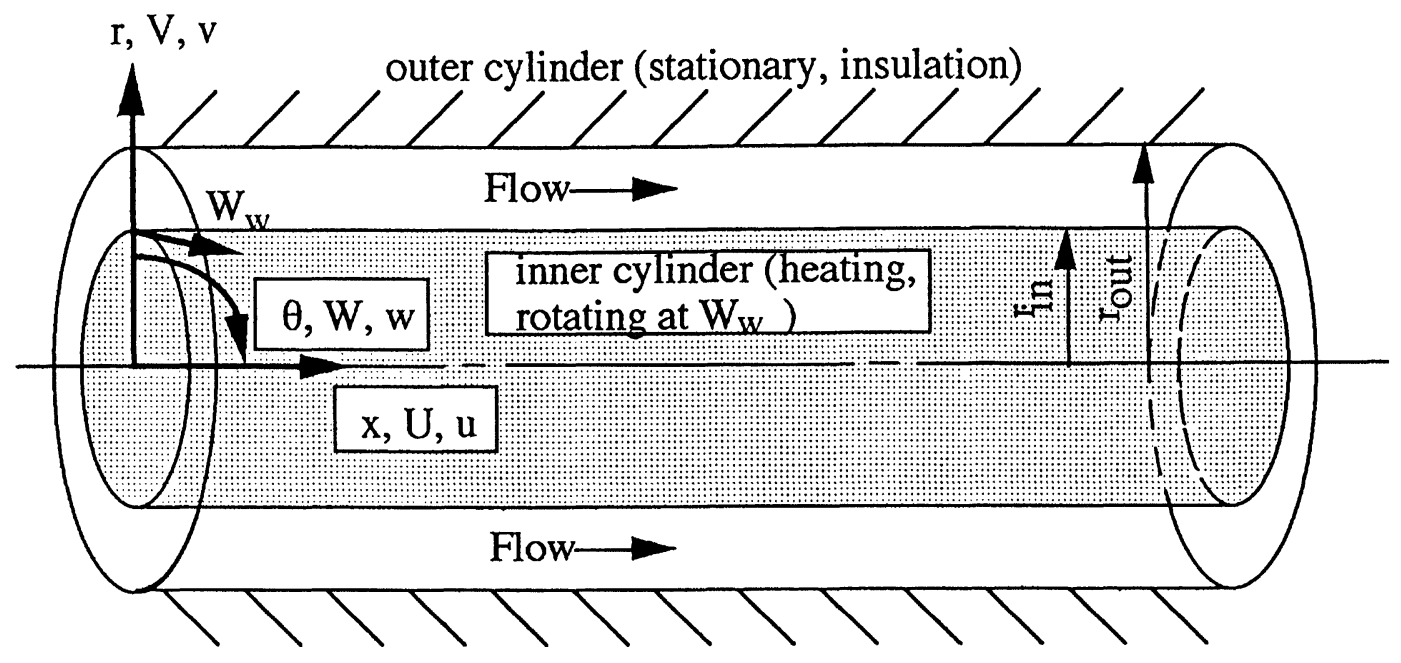

FIGURE 1 A schematic of physical system and coordinate. 
Momentum equations:

$x$ direction:

$$
U \frac{\partial U}{\partial x}+V \frac{\partial U}{\partial r}=-\frac{1}{\rho} \frac{\mathrm{d} P}{\mathrm{~d} x}+\frac{1}{r} \frac{\partial}{\partial r}\left(r \nu \frac{\partial U}{\partial r}-r \overline{u v}\right)
$$

$r$ direction:

$$
\frac{\partial P}{\partial r}=-\rho \frac{\partial \overline{v^{2}}}{\partial r}+\frac{\rho}{r}\left(W^{2}+\overline{w^{2}}-\overline{v^{2}}\right)
$$

$\theta$ direction:

$$
\begin{aligned}
& U \frac{\partial W}{\partial x}+V \frac{\partial W}{\partial r}+\frac{V W}{r} \\
& =\frac{1}{r^{2}} \frac{\partial}{\partial r}\left\{r^{3} \nu \frac{\partial(W / r)}{\partial r}-r^{2} \overline{v w}\right\}
\end{aligned}
$$

Energy equation:

$$
U \frac{\partial T}{\partial x}+V \frac{\partial T}{\partial r}=\frac{1}{r} \frac{\partial}{\partial r}\left(r \alpha \frac{\partial T}{\partial r}-r \overline{v t}\right) .
$$

The Reynolds stress turbulence model proposed by Launder and Shima (1989) is employed to evaluate $-\overline{u v}$ in Eq. (2) and $-\overline{v w}$ in Eq. (4). The transport equations can be expressed as $\overline{u^{2}}$ :

$$
\begin{aligned}
& U \frac{\partial \overline{u^{2}}}{\partial x}+V \frac{\partial \overline{u^{2}}}{\partial r}=\frac{1}{r} \frac{\partial}{\partial r}\left\{r\left(\nu+C_{\mathrm{s}} \frac{k \overline{v^{2}}}{\varepsilon}\right) \frac{\partial \overline{u^{2}}}{\partial r}\right\} \\
& -2\left(1-f_{2}\right) \overline{u v} \frac{\partial U}{\partial r}-f_{1} \overline{u^{2}} \frac{\varepsilon}{k}+\frac{2}{3}\left(f_{1}-1\right) \varepsilon \\
& +f_{1 w} f_{x} \overline{v^{2}} \frac{\varepsilon}{k}-\frac{2}{3}\left(f_{2}+f_{2 w} f_{x}\right) \\
& \times\left(\overline{u v} \frac{\partial U}{\partial r}+\overline{v w} \frac{\partial W}{\partial r}-\overline{v w} \frac{W}{r}-w^{2} \frac{V}{r}\right) \\
& -2 f_{2 w} f_{x} \overline{v w} \frac{W}{r}
\end{aligned}
$$

$\overline{v^{2}}:$

$$
\begin{aligned}
& U \frac{\partial \overline{v^{2}}}{\partial x}+V \frac{\partial \overline{v^{2}}}{\partial r} \\
& =\frac{1}{r} \frac{\partial}{\partial r}\left\{r\left(\nu+C_{\mathrm{s}} \frac{k \overline{v^{2}}}{\varepsilon}\right) \frac{\partial \overline{v^{2}}}{\partial r}\right\}-2\left(\nu+C_{\mathrm{s}} \overline{w^{2}} \frac{k}{\varepsilon}\right) \\
& \times \frac{\overline{v^{2}}-\overline{w^{2}}}{r^{2}}-f_{1} \overline{v^{2}} \frac{\varepsilon}{k}+\frac{2}{3}\left(f_{1}-1\right) \varepsilon-2 f_{1 w} f_{x} \overline{v^{2}} \frac{\varepsilon}{k} \\
& -\frac{2}{3}\left(f_{2}-2 f_{2 w} f_{x}\right)\left(\overline{u v} \frac{\partial U}{\partial r}+\overline{v w} \frac{\partial W}{\partial r}-\overline{v w} \frac{W}{r}-\overline{w^{2}} \frac{V}{r}\right) \\
& +2\left(2-f_{2}-2 f_{2 w} f_{x}\right) \overline{v w} \frac{W}{r}-\frac{2 \partial}{r \partial r}\left(C_{\mathrm{s}} \frac{k}{\varepsilon} \overline{v w}^{2}\right) \\
& -\frac{2}{r} C_{\mathrm{s}} \frac{k}{\varepsilon} \overline{v w} \frac{\partial \overline{v w}}{\partial r},
\end{aligned}
$$

$\overline{w^{2}}$ :

$$
\begin{aligned}
U & \frac{\partial \overline{w^{2}}}{\partial x}+V \frac{\partial \overline{w^{2}}}{\partial r} \\
= & \frac{1}{r} \frac{\partial}{\partial r}\left\{r\left(\nu+C_{\mathrm{s}} \frac{k \overline{v^{2}}}{\varepsilon}\right) \frac{\partial \overline{w^{2}}}{\partial r}\right\}+2\left(\nu+C_{\mathrm{s}} \overline{w^{2}} \frac{k}{\varepsilon}\right) \\
& \times \frac{\overline{v^{2}}-\overline{w^{2}}}{r^{2}}-f_{1} \overline{w^{2}} \frac{\varepsilon}{k}+\frac{2}{3}\left(f_{1}-1\right) \varepsilon+f_{1 w} f_{x} \overline{v^{2}} \frac{\varepsilon}{k} \\
& -\frac{2}{3}\left(f_{2}+f_{2 w} f_{x}\right)\left(\overline{u v} \frac{\partial U}{\partial r}+\overline{v w} \frac{\partial W}{\partial r}-\overline{v w} \frac{W}{r}-\overline{w^{2}} \frac{V}{r}\right) \\
& -2\left(1-f_{2}\right)\left(\overline{v w} \frac{\partial W}{\partial r}-\overline{w^{2}} \frac{V}{r}\right)-2\left(1+f_{2 w} f_{x}\right) \\
& \times \overline{v w} \frac{W}{r}+\frac{2 \partial}{r \partial r}\left(C_{\mathrm{s}} \frac{k}{\varepsilon} \overline{v w^{2}}\right)+\frac{2}{r} C_{\mathrm{s}} \frac{k}{\varepsilon} \overline{v w} \frac{\partial \overline{v w}}{\partial r},
\end{aligned}
$$

$\overline{u v}$ :

$$
\begin{aligned}
U & \frac{\partial \overline{u v}}{\partial x}+V \frac{\partial \overline{u v}}{\partial r} \\
= & \frac{1}{r} \frac{\partial}{\partial r}\left\{r\left(\nu+C_{\mathrm{s}} \frac{k \overline{v^{2}}}{\varepsilon}\right) \frac{\partial \overline{u v}}{\partial r}\right\}-\left(\nu+C_{\mathrm{s}} \overline{w^{2}} \frac{k}{\varepsilon}\right) \frac{\overline{u v}}{r^{2}} \\
& -f_{1} \overline{u v} \frac{\varepsilon}{k}-\frac{3}{2} f_{1 w} f_{x} \overline{u v} \frac{\varepsilon}{k}-\left(1-f_{2}+\frac{3}{2} f_{2 w} f_{x}\right) \overline{v^{2}} \frac{\partial U}{\partial r} \\
& +\left(2-f_{2}+\frac{3}{2} f_{2 w} f_{x}\right) \overline{u w} \frac{W}{r}-\frac{1 \partial}{r \partial r}\left(C_{\mathrm{s}} \frac{k}{\varepsilon} \overline{u w} \overline{v w}\right) \\
& -\frac{1}{r} C_{\mathrm{s}} \frac{k}{\varepsilon} \overline{v w} \frac{\partial \overline{u w}}{\partial r},
\end{aligned}
$$


$\overline{v w}$ :

$$
\begin{aligned}
U & \frac{\partial \overline{v w}}{\partial x}+V \frac{\partial \overline{v w}}{\partial r} \\
= & \frac{1}{r} \frac{\partial}{\partial r}\left\{r\left(\nu+C_{\mathrm{s}} \frac{k \overline{v^{2}}}{\varepsilon} \frac{\partial \overline{v w}}{\partial r}\right\}-4\left(\nu+C_{\mathrm{s}} \overline{w^{2}} \frac{k}{\varepsilon}\right)\right. \\
& \times \frac{\overline{v w}}{r^{2}}-f_{1} \overline{v w} \frac{\varepsilon}{k}-\frac{3}{2} f_{1 w} f_{x} \overline{v w} \frac{\varepsilon}{k}+\left(\overline{w^{2}}-\overline{\dot{v}^{2}}\right) \frac{W}{r} \\
& -\left(1-f_{2}+\frac{3}{2} f_{2 w} f_{x}\right)\left(\overline{v^{2}} \frac{\partial W}{\partial r}-\overline{w^{2}} \frac{W}{r}+\overline{v w} \frac{V}{r}\right) \\
& -\frac{1}{r} \frac{\partial}{\partial r}\left\{C_{\mathrm{s}} \frac{k}{\varepsilon}\left(\overline{w^{2}}-\overline{v^{2}}\right) \overline{v w}\right\} \\
& +\frac{1}{r} C_{\mathrm{s}} \frac{k}{\varepsilon} \overline{v w}\left(\frac{\partial \overline{v^{2}}}{\partial r}-\frac{\partial \overline{w^{2}}}{\partial r}\right),
\end{aligned}
$$

$\overline{u w}$ :

$$
\begin{aligned}
U & \frac{\partial \overline{u w}}{\partial x}+V \frac{\partial \overline{u w}}{\partial r} \\
= & \frac{1}{r} \frac{\partial}{\partial r}\left\{r\left(\nu+C_{\mathrm{s}} \frac{k \overline{v^{2}}}{\varepsilon}\right) \frac{\partial \overline{u w}}{\partial r}\right\}-\left(\nu+C_{\mathrm{s}} \overline{w^{2}} \frac{k}{\varepsilon}\right) \frac{\overline{u w}}{r^{2}} \\
& -f_{1} \overline{u w} \frac{\varepsilon}{k}-\frac{3}{2} f_{1 w} f_{x} \overline{u w} \frac{\varepsilon}{k}-\overline{u w} \frac{W}{r} \\
& -\left(1-f_{2}+\frac{3}{2} f_{2 w} f_{x}\right)\left(\overline{u v} \frac{\partial W}{\partial r}+\overline{v w} \frac{\partial U}{\partial r}+\overline{u w} \frac{V}{r}\right) \\
& +\frac{1}{r} \frac{\partial}{\partial r}\left(C_{\mathrm{s}} \frac{k}{\varepsilon} \overline{u v} \overline{v w}\right)+\frac{1}{r} C_{\mathrm{s}} \frac{k}{\varepsilon} \overline{v w} \frac{\partial \overline{u v}}{\partial r} .
\end{aligned}
$$

Turbulent energy dissipation rate $\varepsilon$ is determined from

$$
\begin{aligned}
U \frac{\partial \varepsilon}{\partial x} & +V \frac{\partial \varepsilon}{\partial r} \\
= & \frac{1}{r} \frac{\partial}{\partial r}\left\{r\left(\nu+C_{\varepsilon} \frac{\left.k-\frac{\partial}{\varepsilon}\right)}{\varepsilon} \frac{\partial \varepsilon}{\partial r}\right\}-\left(C_{\varepsilon 1}+\varphi_{1}+\varphi_{2}\right)\right. \\
& \times \frac{\varepsilon}{k}\left(\overline{u v} \frac{\partial U}{\partial r}+\overline{v w} \frac{\partial W}{\partial r}-\overline{v w} \frac{W}{r}-\overline{w^{2}} \frac{V}{r}\right) \\
& -C_{\varepsilon 2} \frac{\varepsilon}{k}\left\{\varepsilon-2 \nu\left(\frac{\partial \sqrt{k}}{\partial r}\right)^{2}\right\} .
\end{aligned}
$$

The empirical constants and model functions in Eqs. (6)-(12) are summarized in Table I.
The turbulent heat flux $-\overline{v t}$ in Eq. (5) is expressed through Boussinesq's approximation, as

$$
-\overline{v t}=\alpha_{\mathrm{t}} \frac{\partial T}{\partial r} .
$$

Youssef et al. (1992) obtain the turbulent thermal diffusivity, $\alpha_{\mathrm{t}}$, using the temperature variance, $\bar{t}^{2}$, and the dissipation rate of temperature fluctuations $\varepsilon_{\mathrm{t}}$ together with $k$ and $\varepsilon$, as

$$
\alpha_{t}=C_{\lambda} f_{\lambda} k\left(\frac{k}{\varepsilon}\right)^{-1}\left(\frac{\overline{t^{2}}}{\varepsilon_{\mathrm{t}}}\right)^{2},
$$

where $C_{\lambda}$ is the model constant and $f_{\lambda}$ is the model function. Both transport equations, $\bar{t}^{2}$ and $\varepsilon_{\mathrm{t}}$ in Eq. (14), are written in the tensor form as

$$
U_{j} \frac{\partial \overline{t^{2}}}{\partial x_{j}}=\frac{\partial}{\partial x_{j}}\left\{\left(\frac{\alpha_{\mathrm{t}}}{\sigma_{h}}+\alpha\right) \frac{\partial \overline{t^{2}}}{\partial x_{j}}\right\}-2 \overline{u_{j} t} \frac{\partial T}{\partial x_{j}}-2 \varepsilon_{\mathrm{t}},
$$

and

$$
\begin{aligned}
U_{j} \frac{\partial \varepsilon_{\mathrm{t}}}{\partial x_{j}}= & \frac{\partial}{\partial x_{j}}\left\{\left(\frac{\alpha_{\mathrm{t}}}{\sigma_{\phi}}+\alpha\right) \frac{\partial \varepsilon_{\mathrm{t}}}{\partial x_{j}}\right\}-C_{P 1} f_{P 1} \frac{\varepsilon_{\mathrm{t}}}{\overline{t^{2}}} \overline{u_{j} t} \frac{\partial T}{\partial x_{j}} \\
& -C_{\mathrm{P} 2} f_{\mathrm{P} 2} \frac{\varepsilon_{\mathrm{t}}}{k} \overline{u_{i} u_{j}} \frac{\partial U_{i}}{\partial x_{j}}-C_{\mathrm{D} 1} f_{\mathrm{D} 1} \frac{\varepsilon_{\mathrm{t}}^{2}}{\bar{t}^{2}} \\
& -C_{\mathrm{D} 2} f_{\mathrm{D} 2} \frac{\varepsilon \varepsilon_{\mathrm{t}}}{k} .
\end{aligned}
$$

In the present study, the Reynolds stress turbulence model is employed in place of a $k-\varepsilon$ model. Thus a slight modification is made to the turbulent diffusion terms in Eqs. (15) and (16). Original turbulent diffusion terms in both equations are written as $-\overline{u_{j} t^{2}}$ and $-\overline{u_{j} \varepsilon_{\mathrm{t}}^{\prime}}$, respectively. Both terms are modeled using a gradient-type representation and are expressed as

$$
-\overline{u_{j} t^{2}}=C_{\mathrm{st}} \frac{k}{\varepsilon} \overline{u_{i} u_{j}} \frac{\partial \overline{t^{2}}}{\partial x_{i}} \text { and }-\overline{u_{j} \varepsilon_{\mathrm{t}}^{\prime}}=C_{\mathrm{s} \varepsilon} \frac{k}{\varepsilon} \overline{u_{i} u_{j}} \frac{\partial \varepsilon_{\mathrm{t}}}{\partial x_{i}}
$$

respectively (Jones and Musonge, 1988; Sommer et al., 1992). Here $C_{\mathrm{st}}$ and $C_{\mathrm{s} \varepsilon}$ are the diffusion 
TABLE I Empirical constants and functions for a Reynolds stress turbulence model

$\begin{array}{lllll}C_{1}=2.58 & C_{2}=0.75 & C_{1 \mathrm{w}}=1.67 & C_{2 \mathrm{w}}=0.5 & C_{L}=2.5\end{array}$

$C_{\mathrm{s}}=0.22 \quad C_{\varepsilon}=0.18 \quad C_{\varepsilon 1}=1.45 \quad C_{\varepsilon 2}=1.9$

$$
\begin{array}{ll}
A_{2} \quad\left(\frac{\overline{u^{2}}}{k}-\frac{2}{3}\right)^{2}+\left(\frac{\overline{v^{2}}}{k}-\frac{2}{3}\right)^{2}+\left(\overline{\frac{w^{2}}{k}}-\frac{2}{3}\right)^{2}+2\left(\frac{\overline{u v}}{k}\right)^{2}+2\left(\overline{\frac{u w}{k}}\right)^{2}+2\left(\frac{\overline{v w}}{k}\right)^{2} \\
A_{3} \quad\left(\frac{\overline{u^{2}}}{k}-\frac{2}{3}\right)^{3}+\left(\frac{\overline{v^{2}}}{k}-\frac{2}{3}\right)^{3}+\left(\overline{w^{2}} \frac{2}{k}\right)^{3}+3\left(\frac{\overline{u v}}{k}\right)^{2}\left\{\left(\frac{\overline{u^{2}}}{k}-\frac{2}{3}\right)+\left(\frac{\overline{v^{2}}}{k}-\frac{2}{3}\right)\right\}+3\left(\frac{\overline{u w}}{k}\right)^{2}\left\{\left(\frac{\overline{u^{2}}}{k}-\frac{2}{3}\right)+\left(\frac{\overline{w^{2}}}{k}-\frac{2}{3}\right)\right\} \\
& +3\left(\frac{\overline{v w}}{k}\right)^{2}\left\{\left(\overline{v^{2}} \frac{2}{k}-\frac{2}{3}\right)+\left(\overline{w^{2}} \frac{2}{k}-\frac{2}{3}\right)\right\} \\
P & -\overline{u v} \frac{\partial U}{\partial r}-\overline{v w} \frac{\partial W}{\partial r}+\frac{\overline{v w}}{r} W \\
A & 1-\frac{9}{8} A_{2}+\frac{9}{8} A_{3} \\
f_{x} & k^{3 / 2} / C_{L} y \varepsilon \\
f_{\mathrm{R} 1} & 1-\exp \left\{-\left(0.0067 R_{\mathrm{t}}\right)^{2}\right\} \\
f_{\mathrm{R} 2} & \exp \left\{-\left(0.002 R_{\mathrm{t}}\right)^{2}\right\} \\
f_{1} & 1+C_{1} f_{\mathrm{R} 1} A A_{2}^{1 / 4} \\
f_{2} & C_{2} A^{1 / 2} \\
f_{\mathrm{lw}} & -\frac{2}{3} f_{1}+C_{1 \mathrm{w}} \\
f_{2 \mathrm{w}} & \frac{1}{2}\left\{\frac{2}{3}\left(f_{2}-1\right)+C_{2 w}+\left|\frac{2}{3}\left(f_{2}-1\right)+C_{2 \mathrm{w}}\right|\right\} \\
\psi_{1} & 2.5 A\left(\frac{P}{\varepsilon}-1\right) \\
\psi_{2} & 0.3 f_{\mathrm{R} 2}\left(1-0.3 A_{2}\right)
\end{array}
$$

coefficients. From this consideration, transport equations of $\overline{t^{2}}$ and $\varepsilon_{\mathrm{t}}$ for the cylindrical coordinate system in Fig. 1 are expressed as

$$
\begin{aligned}
U \frac{\partial \overline{t^{2}}}{\partial x}+V \frac{\partial \overline{t^{2}}}{\partial r}= & \frac{1}{r} \frac{\partial}{\partial r}\left\{r\left(C_{\mathrm{st}} \frac{k}{\varepsilon} \overline{v^{2}}+\alpha\right) \frac{\partial \overline{t^{2}}}{\partial r}\right\} \\
& +2 \alpha_{\mathrm{t}}\left(\frac{\partial T}{\partial r}\right)^{2}-2 \varepsilon_{\mathrm{t}}
\end{aligned}
$$

and

$$
\begin{aligned}
U \frac{\partial \varepsilon_{\mathrm{t}}}{\partial x} & +V \frac{\partial \varepsilon_{\mathrm{t}}}{\partial r} \\
= & \frac{1}{r} \frac{\partial}{\partial r}\left\{r\left(C_{\mathrm{S} \varepsilon} \frac{k}{\varepsilon} \overline{v^{2}}+\alpha\right) \frac{\partial \varepsilon_{\mathrm{t}}}{\partial_{r}}\right\} \\
& +C_{\mathrm{P} 1} f_{\mathrm{P} 1} \alpha_{\mathrm{t}} \frac{\varepsilon_{\mathrm{t}}}{\overline{t^{2}}}\left(\frac{\partial T}{\partial r}\right)^{2}-C_{\mathrm{P} 2} f_{\mathrm{P} 2} \frac{\varepsilon_{\mathrm{t}}}{k} \overline{u v} \frac{\partial U}{\partial r} \\
& -C_{\mathrm{P} 2} f_{\mathrm{P} 2} \frac{\varepsilon_{\mathrm{t}}}{k} \overline{v w} r\left\{\frac{\partial(W / r)}{\partial r}\right\}-C_{\mathrm{D} 1} f_{\mathrm{D} 1} \frac{\varepsilon_{\mathrm{t}}^{2}}{\bar{t}^{2}} \\
& -C_{\mathrm{D} 2} f_{\mathrm{D} 2} \frac{\varepsilon \varepsilon_{\mathrm{t}}}{k},
\end{aligned}
$$

TABLE II Empirical constants and functions for a twoequation model for thermal transport

$$
\begin{aligned}
& C_{\mathrm{P} 1}=1.70 \quad C_{\mathrm{P} 2}=0.64 \quad C_{\mathrm{st}}=0.11 \quad C_{\mathrm{s} \varepsilon}=0.11 \\
& C_{\mathrm{D} 1}=2.0 \quad C_{\mathrm{D} 2}=0.9 \quad f_{\mathrm{P} 1}=1.0 \quad f_{\mathrm{P} 2}=1.0 \\
& C_{\lambda}=0.10 \quad B_{\lambda}=3.4 \quad C_{\varepsilon 2^{\prime}}=1.9 \quad A_{\lambda}=26 / \mathrm{Pr}^{0.5} \\
& R_{\mathrm{h}} \quad(k / \nu)(k / \varepsilon)^{-1}\left(\overline{t^{2}} / \varepsilon_{\mathrm{t}}\right)^{2} \\
& f_{\mathrm{D} 1} \quad\left\{1-\exp \left(-y^{+} / 5.8\right)\right\}^{2} \\
& f_{\mathrm{D} 2}\left(1 / C_{\mathrm{D} 2}\right)\left(C_{\varepsilon 2^{\prime}} f_{2^{\prime}}-1\right)\left\{1-\exp \left(-y^{+} / 6\right)\right\}^{2} \\
& f_{\lambda} \quad\left\{1-\exp \left(-y^{+} / A_{\lambda}\right)\right\}^{2}\left(1+B_{\lambda} / R_{\mathrm{h}}^{3 / 4}\right) \\
& f_{2^{\prime}} \quad 1-0.3 \exp \left\{-\left(R_{\mathrm{t}} / 6.5\right)^{2}\right\}
\end{aligned}
$$

respectively. The empirical constants and model functions in Eqs. (14), (18) and (19) are summarized in Table II.

The boundary conditions at both the inner and outer walls in the annulus are specified as, 
$r=r_{\text {in }}($ inner tube wall):

$$
\begin{gathered}
U=V=\overline{u^{2}}=\overline{v^{2}}=\overline{w^{2}}=\overline{u v}=\overline{v w}=\overline{u w}=0, \\
W=W_{\mathrm{w}}, \quad \varepsilon=2 \nu\left(\frac{\partial \sqrt{k}}{\partial r}\right)^{2}, \\
\frac{\partial \bar{t}^{2}}{\partial r}=0, \quad \varepsilon_{\mathrm{t}}=\alpha \frac{\partial^{2}\left(\bar{t}^{2} / 2\right)}{\partial r^{2}}, \quad-\frac{\partial T}{\partial \dot{r}}=\frac{q_{\mathrm{w}}}{\lambda_{\mathrm{w}}}
\end{gathered}
$$

$r=r_{\text {out }}$ (outer tube wall):

$$
\begin{gathered}
U=V=W=\overline{u^{2}}=\overline{v^{2}}=\overline{w^{2}}=\overline{u v}=\overline{v w}=\overline{u w}=0, \\
\varepsilon=2 \nu\left(\frac{\partial \sqrt{k}}{\partial r}\right)^{2}, \quad \frac{\partial \bar{t}^{2}}{\partial r}=0, \quad \varepsilon_{\mathrm{t}}=\alpha \frac{\partial^{2}\left(\bar{t}^{2} / 2\right)}{\partial r^{2}}, \\
\frac{\partial T}{\partial r}=0 \quad \text { (insulation). }
\end{gathered}
$$

\section{Numerical Method}

A set of governing equations employed are discretized using a control volume finite-difference procedure proposed by Patankar (1980). Since all turbulence quantities as well as the time-averaged axial and tangential velocities vary rapidly in the near-wall region, two control volumes are always located within the viscous sublayer, $y^{+}=5$. The radial mesh size is increased from a minimum value adjacent to the wall towards the turbulent core region in geometrical proportion, and the maximum control volume size in the turbulent core region is always kept within $3 \%$ of $D / 2$. Meanwhile, the axial control volume size is constant at five times the minimum radial size for the wall. Throughout numerical calculations, the number of control volumes in the radial direction was properly selected between 70 and 92 to ensure validation of the numerical procedures as well as to obtain grid-independent solutions. The maximum relative error over all dependent variables within this change of grid spacing was kept within $1 \%$. Since the governing equations are essentially parabolic, calculation is performed from the inlet in the downstream direction by means of the marching procedure. The computations are processed in the following order:
1. Specify the initial values of $U, V, \overline{u^{2}}, \overline{v^{2}}, \overline{w^{2}}$, $\overline{u v}, \overline{v w}, \overline{u w}$, and $\varepsilon$, and assign a constant axial pressure gradient.

2. Solve the equations of $U, V, \overline{u^{2}}, \overline{v^{2}}, \overline{w^{2}}, \overline{u v}, \overline{v w}$, $\overline{u w}$, and $\varepsilon$.

3. Repeat step 2 until the criterion of convergence is satisfied, which is set at

$$
\max \left|\frac{\phi^{M}-\phi^{M-1}}{\phi_{\max }^{M-1}}\right|<10^{-4}
$$

for all the variables $\phi$. The superscripts $M$ and $M-1$ in Eq. (20) indicate two successive iterations, while the subscript "max" refers to a maximum value over the entire fields of iterations.

4. Calculate new values of $U, V, \overline{u^{2}}, \overline{v^{2}}, \overline{w^{2}}, \overline{u v}, \overline{v w}$, $\overline{u w}$, and $\varepsilon$ with a corrected new axial pressure gradient.

5. Repeat steps 2-4 until the conservation of the total mass flow rate is satisfied under the criterion:

$$
\left|\frac{\iint U_{\mathrm{cp}} \theta \mathrm{d} r-\iint U_{\text {inlet }} \theta \mathrm{d} r}{\iint U_{\text {inlet }} \theta \mathrm{d} r}\right| \leq 10^{-5},
$$

followed by evaluating convergent values of $U$, $V, \overline{u^{2}}, \overline{v^{2}}, \overline{w^{2}}, \overline{u v}, \overline{v w}, \overline{u w}$, and $\varepsilon$. $U_{\mathrm{cp}}$ is the axial velocity under the correction process and $U_{\text {inlet }}$ is that at the inlet of the annulus.

6. Repeat steps 2-5 until a hydrodynamically fully-developed annular flow in the absence of rotation is realized.

7. Start both axial rotation and heating of an inner cylinder.

8. Solve the equations of $U, V, W, \overline{u^{2}}, \overline{v^{2}}, \overline{w^{2}}, \overline{u v}$, $\overline{v w}, \overline{u w}, \varepsilon, T, \overline{t^{2}}$, and $\varepsilon_{\mathrm{t}}$.

9. Repeat step 8 until the criterion of convergence, Eq. (20), is satisfied.

10. Calculate new values of $U, V, W, \overline{u^{2}}, \overline{v^{2}}, \overline{w^{2}}, \overline{u v}$, $\overline{v w}, \overline{u w}, \varepsilon, T, \overline{t^{2}}$, and $\varepsilon_{\mathrm{t}}$ with a corrected new axial pressure gradient.

11. Repeat steps $8-10$ until the conservation of the total mass flow rate is satisfied under the criterion, i.e. Eq. (21), followed by evaluating 
convergent values of $U, V, W, \overline{u^{2}}, \overline{v^{2}}, \overline{w^{2}}, \overline{u v}, \overline{v w}$, $\overline{u w}, \varepsilon, T, \overline{t^{2}}$, and $\varepsilon_{\mathrm{t}}$.

12. Repeat steps $8-11$ until $x$ reaches the designated length $(200 D)$, where thermally and hydrodynamically fully-developed flow condition prevails.

The ranges of the parameters for the present study are Reynolds number $\mathrm{Re}=6000-10,000$; Taylor numbers $\mathrm{Ta}=0$ and 5000 ; radius ratio $r^{*}=0.8$; Prandtl number $\operatorname{Pr}=0.7$ (air); and heat flux at the inner wall $q_{\mathrm{w}}=200 \mathrm{~W} / \mathrm{m}^{2}$. The CPU time required in completing the above scheme was about $50-100 \mathrm{~h}$ on a NEC personal computer (32 bit), depending on the number of control volumes used.

It is necessary to verify both the turbulence models of heat and momentum employed here and the reliability of the computer code by comparing numerical predictions with experimental results for the flow field. The model is applied to a flow in an annulus with a stationary, slightly heated inner core. Numerical results for the thermally and hydrodynamically fully-developed annular flow at a location 200 tube diameter downstream from the inlet are compared with the experimental data $\left(\mathrm{Re}=46,000\right.$ and $\left.r^{*}=0.56\right)$ of Brighton and Jones (1964). Figure 2 presents the Nusselt number as a function of the Reynolds number. Dalle Donne and Meerwald (1966) derived the following correlation for the Nusselt number at the inner wall of the annulus as

$\mathrm{Nu}=0.0181\left(\frac{r_{\text {out }}}{r_{\text {in }}}\right)^{0.2} \operatorname{Re}^{0.8} \operatorname{Pr}^{0.4}\left(\frac{T_{\text {win }}}{T_{\text {inlet }}}\right)^{-0.18}$.

This equation is superimposed in Fig. 2 as a solid straight line. It should be noted that Fig. 2 is under the temperature ratio of the inner wall to the inlet fluid, $T_{\text {win }} / T_{\text {inlet }}$, of unity, and the radius ratio, $r^{*}$, of 0.56 . The calculated Nusselt number is in good agreement with the correlation, Eq. (22). Figure 3 depicts the radial distributions of the time-averaged streamwise velocity (dimensionless velocity $u^{+}$versus $y^{+}$). (a) and (b) of Fig. 3 correspond to the distributions from the inner and outer walls to the location of the maximum streamwise velocity,

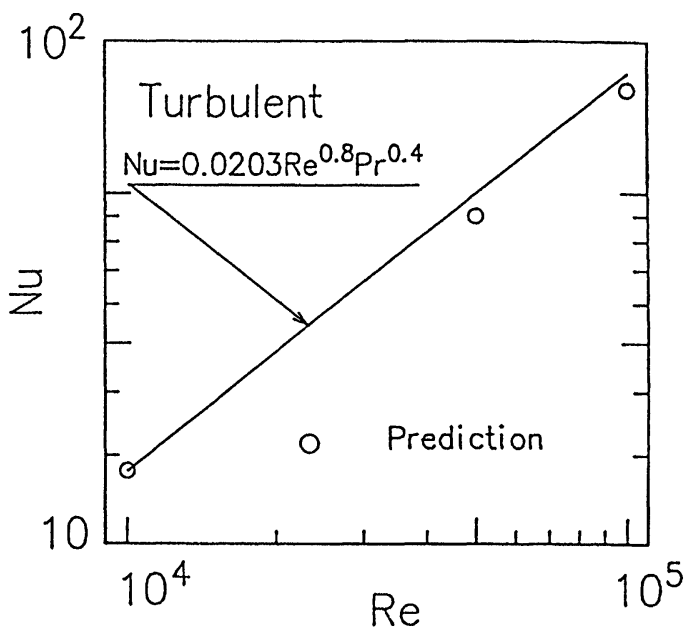

FIGURE 2 A comparison of Predicted Nusselt number with test results (Dalle Donne and Meerwald, 1966) for the fullydeveloped turbulent annular flow with a stationary inner cylinder for $r^{*}=0.56$ and $\operatorname{Re}=46,000$.

respectively. It is observed that the model yields a better agreement with the experimental data, and predicts the velocity profile with the well-known characteristics of the logarithmic region, i.e. the universal wall law. Figure 4 illustrates the radial distributions of three normal components of the Reynolds stress tensor. The numerical results are normalized by the friction velocity, $u_{\text {out }}^{*}$, on the outer wall. The model predicts an inherent anisotropy of the annular flow, although its accuracy is somewhat inferior near the inner and outer walls than in the center region. The predicted radial distribution of the time-averaged temperature in the inner wall side is illustrated in Fig. 5 in the form of $T_{\text {in }}^{+}$versus $y_{\text {in }}^{+}$. It is observed that the twoequation heat transfer model reproduces the law of the wall for a thermal boundary layer. Through the above comparisons, the validity of the computer code and the accuracy for the turbulence models of heat and momentum employed here are confirmed.

\section{RESULTS AND DISCUSSION}

Figure 6 , for $r^{*}=0.8$, illustrates numerical results of the Nusselt number with the Taylor number, Ta, 


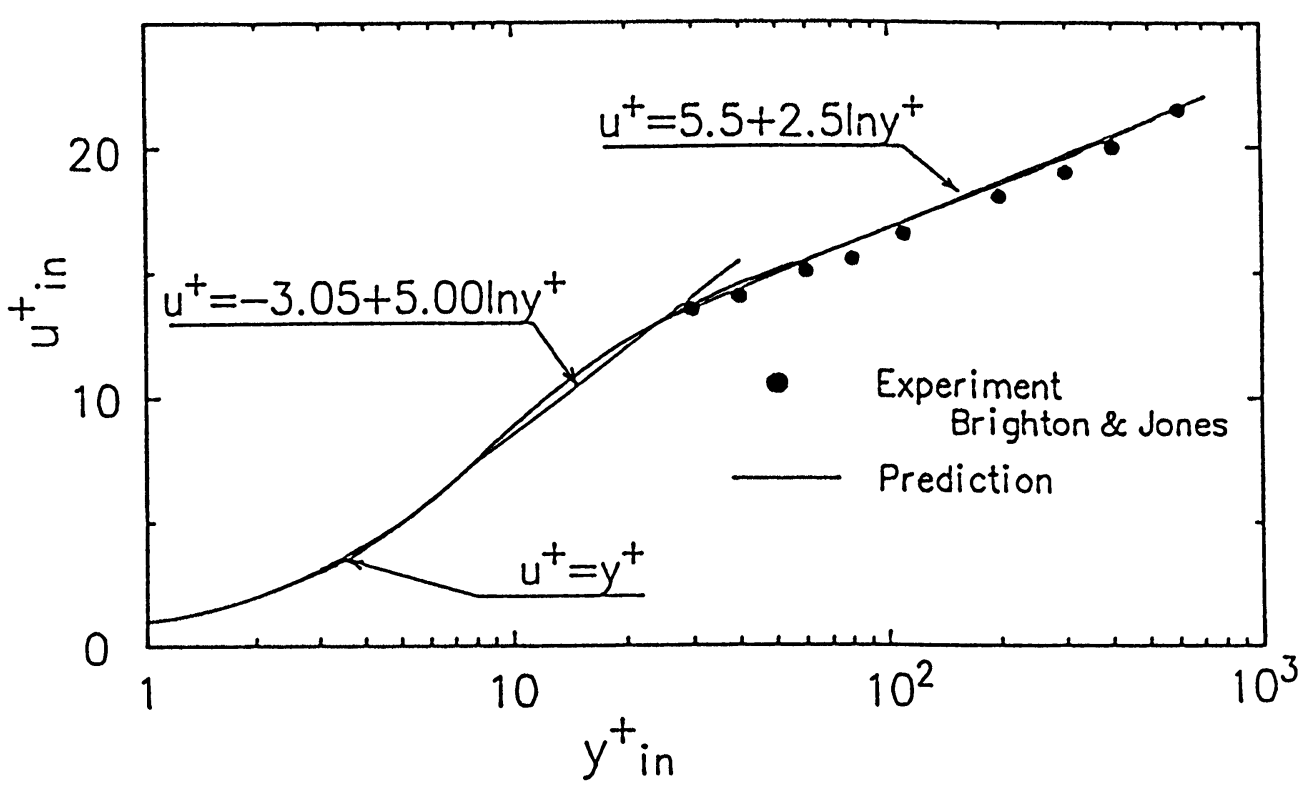

(a) inner side

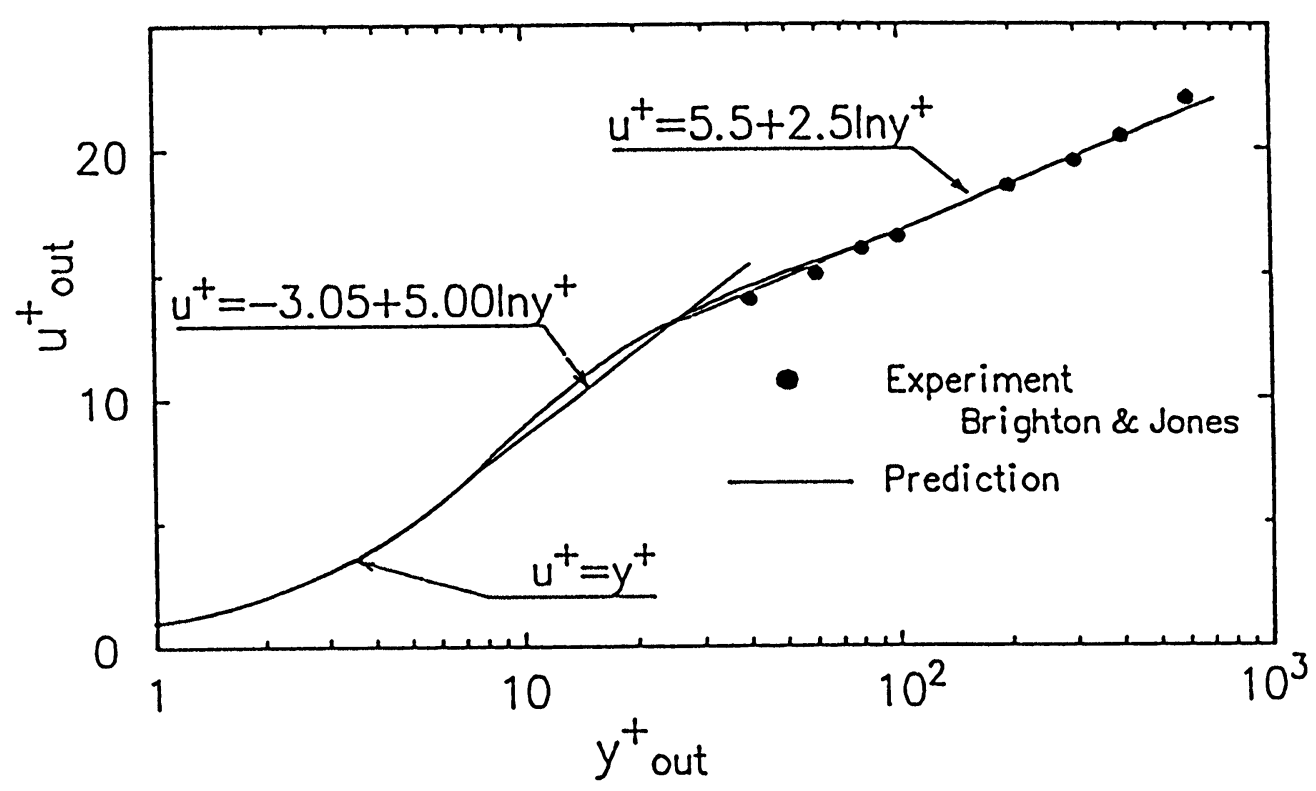

(b) outer side

FIGURE 3 Dimensionless time-averaged streamwise velocity distribution in a stationary concentric annulus for $r^{*}=0.56$ and $\operatorname{Re}=46,000$; (a) inner side and (b) outer side. 


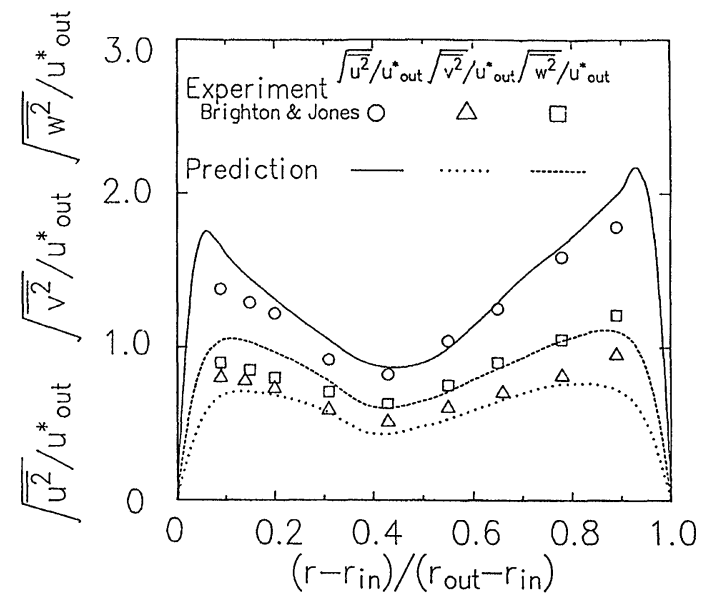

FIGURE 4 A comparison of numerical and experimenta results for radial distribution of normal Reynolds stresses in a stationary concentric annulus for $r^{*}=0.56$ and $\mathrm{Re}=46,000$.



FIGURE 5 Dimensionless time-averaged temperature distribution in a stationary concentric annulus for $r^{*}=0.56$ and $\operatorname{Re}=46,000$.

as the parameter. Equation (22), which is under $r^{*}=0.8$, is superimposed on Fig. 6 as a solid straight line. It is observed that the Nusselt number increases with an increase in the Taylor number. This trend becomes larger in the low Reynolds number region. A similar result is reported by Torii and Yang (1994), who employ the existing $k-\varepsilon$ turbulence models. It is found that an amplification of the Nusselt number is attributed to the axial rotation of the inner cylinder.

An attempt is made to explore the mechanisms of transport phenomena of circular Couette flows in an annulus based on numerical results at $\operatorname{Re}=10,000$ and $r^{*}=0.8$. Figures 7(a) and (b) show the radial distributions of time-averaged streamwise and tangential velocities, respectively. In both

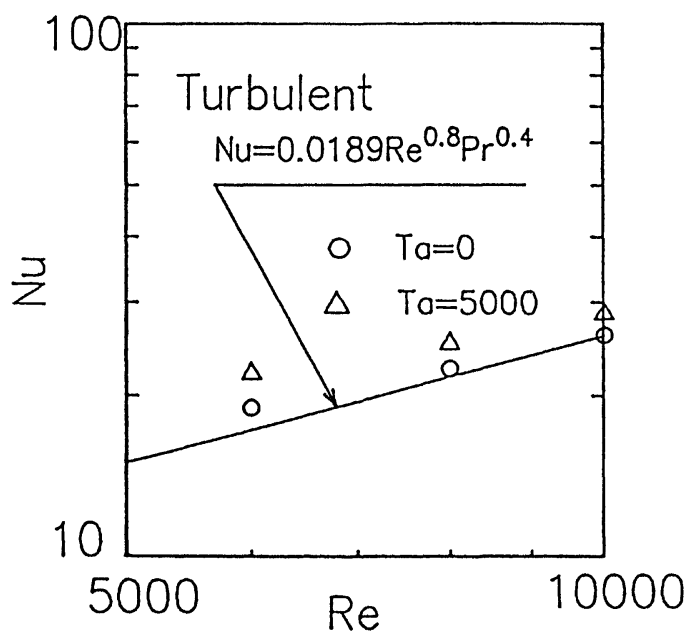

FIGURE 6 Variation of predicted Nusselt numbers in a circular Couette flow at $\mathrm{Ta}=0$ and 5000 for $r^{*}=0.8$.

figures, the velocity is divided by its maximum value at each Taylor number. Here, the maximum tangential velocity corresponds to the tangential one on the inner cylinder. The streamwise velocity profile at $\mathrm{Ta}=0$ corresponds to a turbulent annular flow in the absence of rotation, as seen in Fig. 7(a). The corresponding tangential velocity in Fig. 7(b) is zero over the flow cross section. One observes that the streamwise and tangential velocity gradients increase near the inner and outer walls due to the inner core rotation. Figures $8(a)$ and (b) illustrate the radial variations of the Reynolds stresses, $\overline{u v}$ and $\overline{v w}$ with a change in Ta. The numerical results are divided by the square of the friction velocity, $u_{\text {out }}^{*}$, on the outer wall for the annular flow without the swirl. The Reynolds stress, $\overline{u v}$, near the wall regions is induced with an increase in Ta. This trend becomes larger in the vicinity of the inner wall, as shown in Fig. 8(a). In Fig. 8(b), the Reynolds stress $\overline{v w}$ at $\mathrm{Ta}=0$ disappears over the whole cross section of the flow, while it is coursed by the swirl. The similar result, which is obtained in the isothermal circular Couette flow in an annulus, is reported by Hirai et al. (1987). These behavior is in accord with the variations of the streamwise and tangential velocities in Figs. 7(a) and (b). The radial profiles of three normal components of the Reynolds stress 


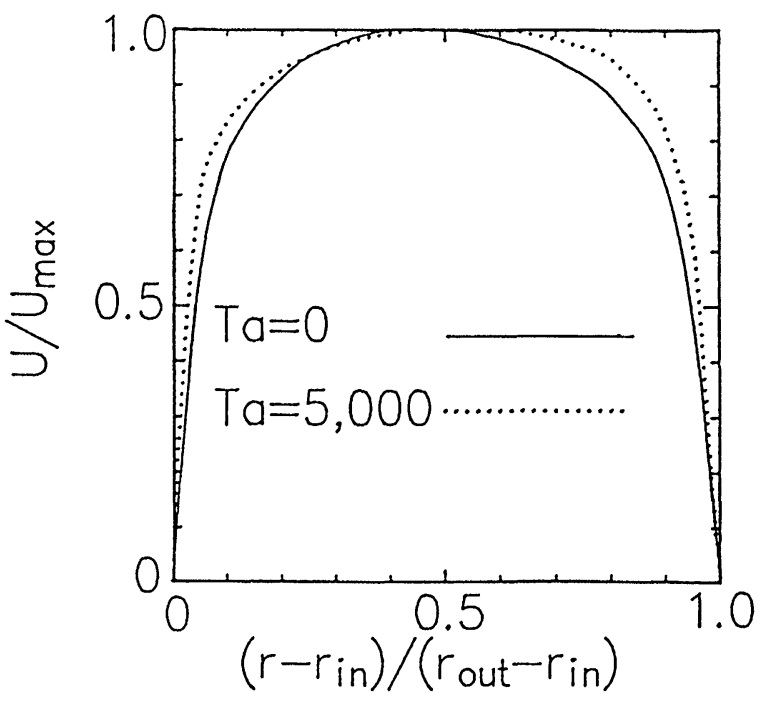

(a) streamwise velocity

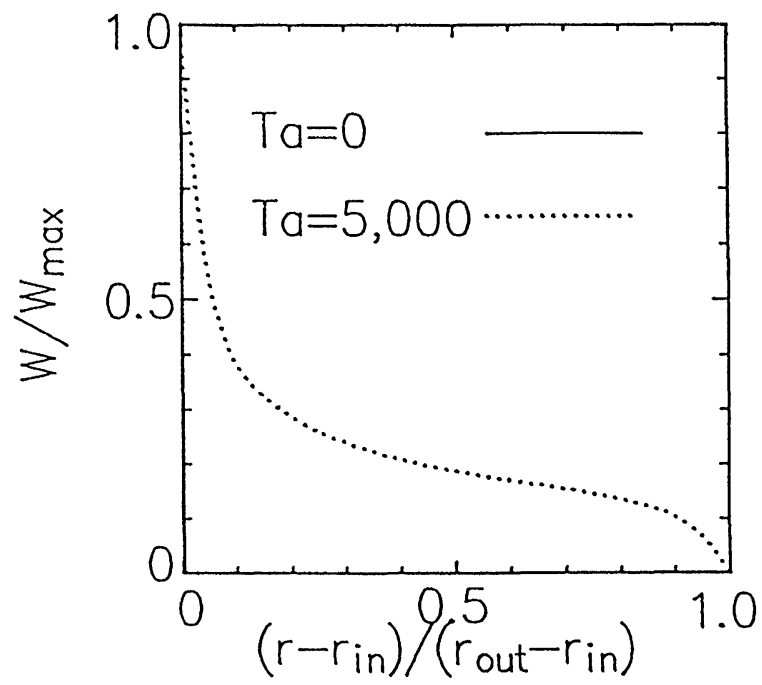

FIGURE 7 Variation of time-averaged velocity profiles in a circular Couette flow at $\mathrm{Ta}=0$ and 5000 for $r^{*}=0.8$ and $\mathrm{Re}=6000$; (a) streamwise velocity and (b) tangential velocity.

are illustrated in Fig. 9 in the same form as Fig. 4 at $\mathrm{Ta}=0$ and 5000 . One observes that (i) the three normal stress levels over the annular cross section are intensified due to the inner core rotation, and (ii) this effect becomes larger near the wall sides. Thus this variation corresponds to the enhancement in the turbulent kinetic energy.

The radial distribution of the predicted turbulent heat flux is depicted in Fig. 10 as a function of Ta.

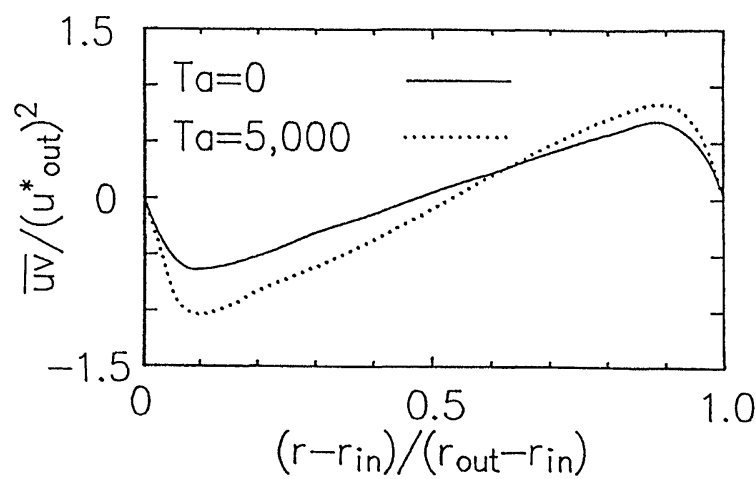

(a) $\overline{u v}$ component



(b) $\overline{\mathrm{vw}}$ component

FIGURE 8 Variation of Reynolds stress profiles in a circular Couette flow at $\mathrm{Ta}=0$ and 5000 for $r^{*}=0.8$ and $\mathrm{Re}=6000$; (a) $\overline{u v}$ component and $\overline{v w}$ component.

Here, the turbulent heat flux is normalized by the product of the friction temperature $t^{*}$ and the friction velocity $u^{*}$ on the outer wall for the annular flow in the absence of the inner core rotation. The turbulent heat flux level in the vicinity of the inner wall is substantially induced with an increase in Ta. Since the eddy diffusivity for heat is employed to determine the turbulent heat flux, it is directly related to the turbulent kinetic energy, its dissipation rate, the temperature variance, and the dissipation rate of temperature fluctuations, through Eqs. (13) and (14). Here turbulent thermal diffusivity $\alpha_{\mathrm{t}}$ is rewritten using the time-scale ratio, $\tau_{\mathrm{m}}$, as

$$
\alpha_{\mathrm{t}}=C_{\lambda} f_{\lambda} \frac{k^{2}}{\varepsilon}\left(2 \tau_{\mathrm{m}}\right)^{2}
$$




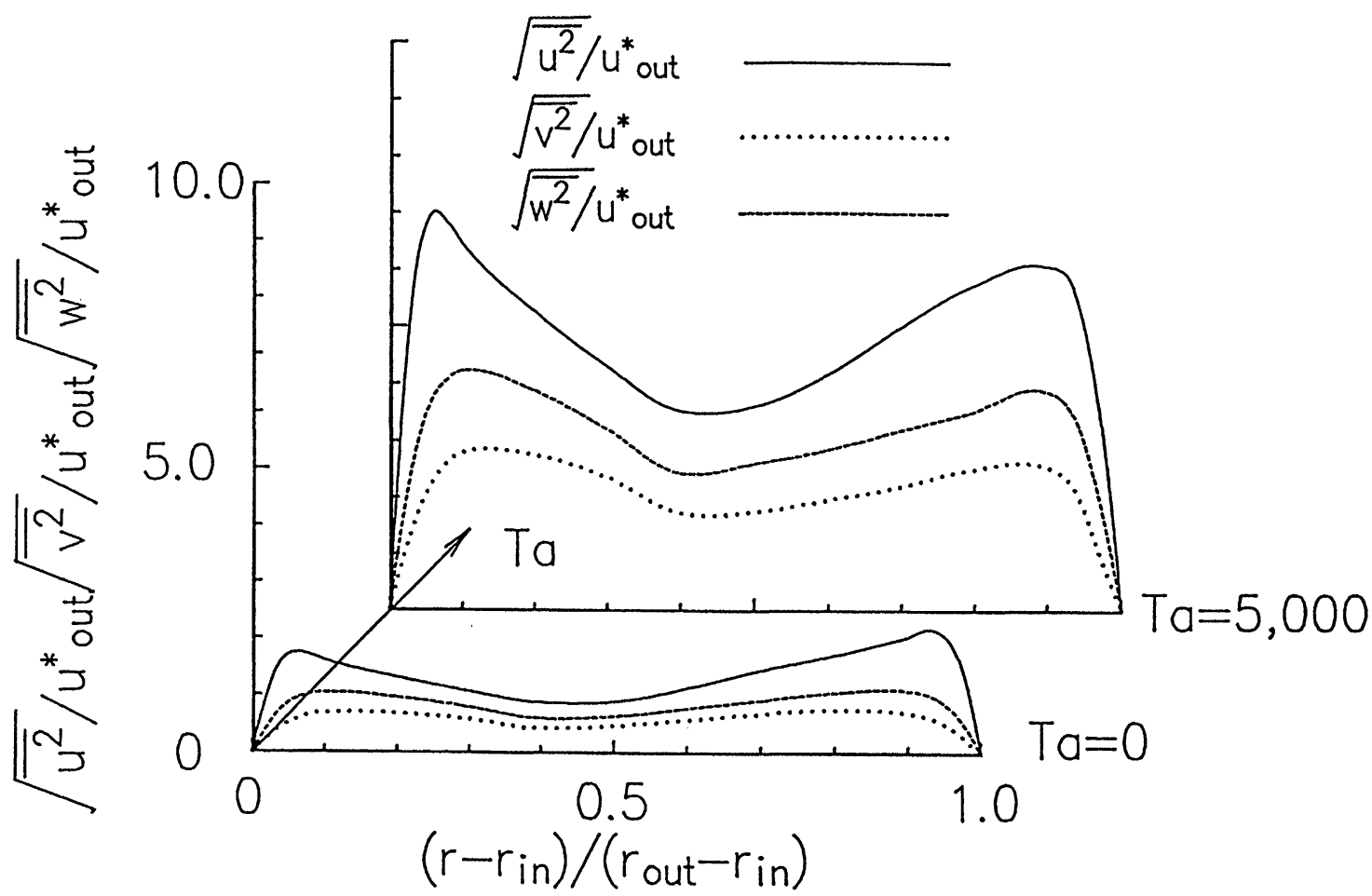

FIGURE 9 Variation of normal Reynolds stress profiles in a circular Couette flow at $\mathrm{Ta}=0$ and 5000 for $r^{*}=0.8$ and $\mathrm{Re}=6000$.

The predicted radial change in the time-scale ratio with the inner core rotation (i.e. Ta) is depicted in Fig. 11. Based on the asymptotic behavior of the turbulent quantities of velocity and thermal fields near the wall, the time-scale ratio becomes infinite under the condition of uniform wall heat flux (Youssef et al., 1992). The numerical result at $\mathrm{Ta}=0$ reproduces this behavior in the vicinity of the inner wall. As $y_{\text {in }}^{+}$is increased, the predicted time-scale ratio approaches a constant value, i.e. about 0.5 , whose value is in good agreement with that reported by Béguier et al. (1978). It is observed that the radial profile of the time-scale ratio at $\mathrm{Ta}=5000$ is affected by the inner core rotation, with only a slight change over the entire flow cross section. Hence, a substantial enhancement in the three normal components of the Reynolds stress, i.e. the turbulent kinetic energy is ascribed to an increase in the Nusselt number, as shown in Fig. 6.

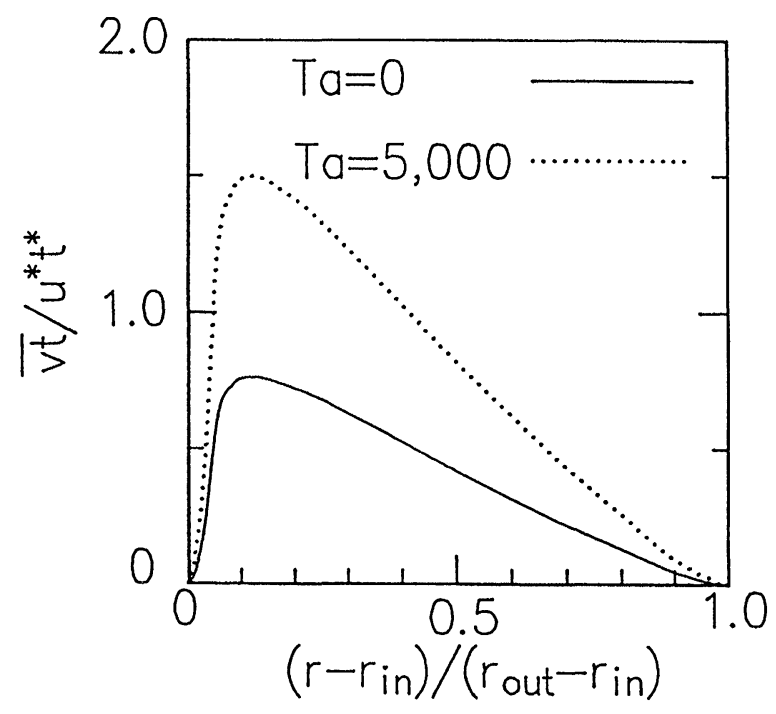

FIGURE 10 Variation of turbulent heat flux profiles in a circular. Couette flow at $\mathrm{Ta}=0$ and 5000 for $r^{*}=0.8$ and $\operatorname{Re}=6000$ 


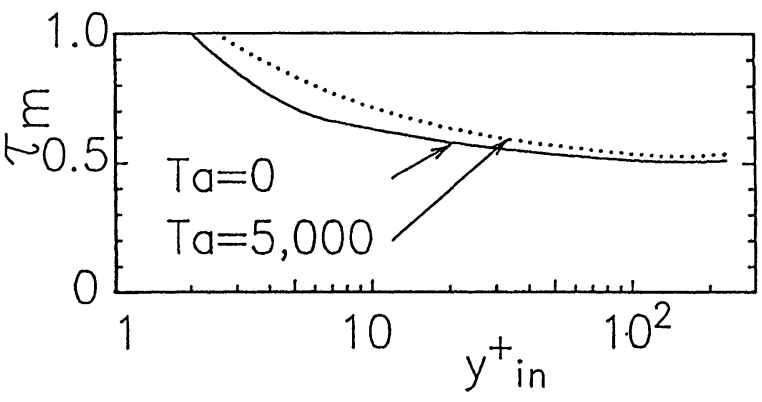

FIGURE 11 Variation of radial profiles of time-scale ratio in a circular Couette flow at $\mathrm{Ta}=0$ and 5000 for $r^{*}=0.8$ and $\mathrm{Re}=6000$.

In summary, an increase in the Nusselt number, as seen in Fig. 6, is caused by the axial rotation of the inner cylinder. The mechanism is that (i) an inner core rotation courses an increase in the streamwise velocity gradient near the inner and outer walls and a presence of the tangential velocity, (ii) the tangential velocity induces a production of the three normal components of the Reynolds stress, and (iii) it yields an enhancement in the turbulent thermal diffusivity, i.e. an amplification of the turbulent heat flux, resulting in an augmentation of heat transfer performance.

\section{CONCLUSIONS}

The two-equation model for heat transfer and the Reynolds stress turbulence model have been employed to numerically investigate the thermal transport phenomena in concentric annulus with a slightly heated inner core rotating around the axis. Consideration is given to the influence of inner core rotation on the flow and thermal fields. The results derived from the present study are summarized as follows.

The turbulence models of heat and momentum employed in this work predict an increase in the Nusselt number due to an axially rotating inner cylinder. It is disclosed that (i) the inner core rotation induces the streamwise velocity gradient near the inner and outer walls and causes the tangential velocity, (ii) the presence of the tangential velocity intensifies the three normal components of the Reynolds stress, resulting in an amplification of the turbulent heat flux, and (iii) an effect of inner core rotation on the time-scale ratio, which is used to determine the turbulent thermal diffusivity in Eq. (23), is minor over the flow cross section. Consequently, the turbulent kinetic energy is induced due to the axial rotation of the inner cylinder, resulting in the enhancement of heat transfer performance.

\section{NOMENCLATURE}

$D \quad$ hydraulic diameter of the annulus, $2\left(r_{\text {out }}-r_{\text {in }}\right), \mathrm{m}$

$h \quad$ heat transfer coefficient, $\mathrm{W} / \mathrm{m}^{2} \mathrm{~K}$

$k \quad$ turbulent kinetic energy, $\left(\overline{u^{2}}+\overline{v^{2}}+\overline{w^{2}}\right) /$ $2, \mathrm{~m}^{2} / \mathrm{s}^{2}$

$\mathrm{Nu} \quad$ Nusselt number, $h U_{\mathrm{m}} / \lambda$

$P \quad$ time-averaged pressure, $\mathrm{Pa}$

Pr Prandtl number

$\mathrm{Pr}_{\mathrm{t}} \quad$ turbulent Prandtl number

$\mathrm{Pe} \quad$ Peclet number

$q \quad$ heat flux, $\mathrm{W} / \mathrm{m}^{2}$

$r \quad$ radial coordinate, $\mathrm{m}$

$r^{*} \quad$ radius ratio, $r_{\text {in }} / r_{\text {out }}$

$r_{\text {in }} \quad$ inner radius of the annulus, $m$

$r_{\text {out }} \quad$ outer radius of the annulus, $m$

Re Reynolds number, $U_{\mathrm{m}} D / \nu$

$R_{\mathrm{t}} \quad$ turbulent Reynolds number, $k^{2} / \varepsilon \nu$

$t \quad$ fluctuating temperature component, $\mathrm{K}$

$\bar{t}^{2} \quad$ temperature variance, $\mathrm{K}^{2}$

$t^{*} \quad$ friction temperature, $q_{\mathrm{w}} / \rho c_{\mathrm{p}} u^{*}, \mathrm{~K}$

$T \quad$ time-averaged temperature, $\mathrm{K}$

$T^{+} \quad$ dimensionless time-averaged temperature, $\left(T_{\mathrm{w}}-T\right) /\left(q_{\mathrm{w}} / \rho c_{\mathrm{p}} u^{*}\right)$

Ta Taylor number, $\mathrm{Ta}=\frac{W_{\mathrm{w}}\left(r_{\text {out }}-r_{\text {in }}\right)}{\nu} \sqrt{\frac{r_{\text {out }}-r_{\text {in }}}{r_{\text {in }}}}$

$u, v, w \quad$ fluctuating velocity components in axial, radial and tangential directions, respectively, $\mathrm{m} / \mathrm{s}$

$u^{*} \quad$ friction velocity, $\mathrm{m} / \mathrm{s}$

$u^{+} \quad$ dimensionless velocity, $U / u^{*}$ 


$\begin{array}{ll}\overline{u v}, \overline{v w}, \overline{u w} & \text { Reynolds stress, } \mathrm{m}^{2} / \mathrm{s}^{2} \\ U, V, W & \begin{array}{l}\text { time-averaged velocity components } \\ \text { in axial, radial and tangential direc- } \\ \text { tions, respectively, } \mathrm{m} / \mathrm{s}\end{array} \\ & \text { axial mean velocity over tube cross } \\ U_{\mathrm{m}} & \text { section, } \mathrm{m} / \mathrm{s} \\ & \text { turbulent heat flux, } \mathrm{mK} / \mathrm{s} \\ -\overline{v t} & \text { tangential velocity on the inner } \\ W_{\mathrm{w}} & \text { cylinder, } \mathrm{m} / \mathrm{s} \\ & \text { axial coordinate, } \mathrm{m} \\ x & \text { distance from wall, } \mathrm{m} \\ y & \text { dimensionless distance, } u^{*} y / \nu\end{array}$

\section{Greek Letters}

$\varepsilon \quad$ turbulent energy dissipation rate, $\mathrm{m}^{2} / \mathrm{s}^{3}$

$\varepsilon_{\mathrm{t}} \quad$ dissipation rate of $\overline{t^{2}}, \mathrm{~K} / \mathrm{s}^{2}$.

$\alpha, \alpha_{\mathrm{t}} \quad$ molecular and turbulent thermal diffusivities, $\mathrm{m}^{2} / \mathrm{s}$

$\nu, \nu_{\mathrm{t}} \quad$ molecular and turbulent viscosities, $\mathrm{m}^{2} / \mathrm{s}$

$\lambda$ molecular thermal conductivity, $\mathrm{W} / \mathrm{mK}$

$\rho \quad$ density of gas, Pasec

$\theta \quad$ tangential direction

$\tau_{\mathrm{m}} \quad$ time-scale ratio, $\left(\overline{t^{2}} / 2 \varepsilon_{\mathrm{t}}\right) /(k / \varepsilon)$

\section{Subscripts}

$\begin{array}{ll}\text { in } & \text { inner side } \\ \text { inlet } & \text { inlet } \\ \text { max } & \text { maximum } \\ \text { out } & \text { outer side } \\ \text { w } & \text { wall }\end{array}$

\section{References}

Beguier, C., Dekeyser, I. and Launder, B.E., 1978. Ratio of Scalar and Velocity Distribution Time Scales in Shear Flow Turbulence, Physics of Fluids, 21, 307-310.

Bradshaw, P., 1969. The Analogy between Streamline Curvature and Buoyancy in Turbulent Shear Flow, J. Fluid Mech., 36, 177-191.

Brighton, J.A. and Jones, J.B., 1964. Fully Developed Turbulent Flow in Annuli, Trans. of ASME, Ser. D, 835-844.

Dalle Donne, M. and Meerwald, E., 1966. Experimental Loca Heat Transfer and Average Friction Coefficients for Subsonic Turbulent Flow of Air in an Annulus at High Temperatures, Int. J. Heat Mass Transfer, 9, 1361-1376.

Hirai, S. and Takagi, T., 1988. Prediction of Heat Transfer Deterioration in Turbulent Swirling Pipe Flow, JSME Int. J. Ser. II, 31(4), 694-700.
Hirai, S., Takagi, T., Tanaka, K. and Kida, K., 1987. Effect of Swirl on the Turbulent Transport of Momentum in a Concentric Annulus with a Rotating Inner Cylinder, Trans., $J S M E$, 53(486), 432-437 (in Japanese).

Hishida, M., Nagano, Y. and Tagawa, M., 1986. Transport Processes of Heat and Momentum in the Wall Region of Turbulent Pipe Flow, Proc. Eighth Int., Heat Transfer Conf., 3, 925-930.

Jones, W.P. and Musonge, P., 1988. Closure of the Reynolds Stress and Scalar Flux Equations, Physics of Fluids, 31(12), 3589-3604.

Kasagi, N. and Myong, H.K., 1989. An Outlook: Modeling of Turbulent Heat Transport, J. Heat Transfer Society of Japan, 28(108), 4-17.

Kasagi, N., Tomita, Y. and Kuroda, A., 1992. Direct Numerical Simulation of Passive Scalar Field in a Turbulent Channel Flow, J. Heat Transfer, 114, 598-606.

Kikuyama, K., Murakami, M., Nishibori, K. and Maeda, K., 1983. Flow in an Axially Rotating Pipe (A calculation of flow in the saturated region), Bulletin of the JSME, 26(214), 506-513.

Kuzay, T.M. and Scott, C.J., 1975. Turbulent Heat Transfer Studies in Annulus with Inner Cylinder Rotation, Trans. of $A S M E, 75-\mathrm{WA} / \mathrm{HT}-55,1-11$

Kuzay, T.M. and Scott, C.J., 1976. Turbulent Prandtl Numbers for Fully Developed Rotating Annular Axial Flow of Air, Trans. of ASME, 76-HT-36, 1-13.

Lai, Y.G. and So, R.M.C., 1990. Near-Wall Modeling of Turbulent Heat Fluxes, Int. J. Heat Mass Transfer, 33(7), 1429-1440.

Launder, B.E. and Shima, N., 1989. Second-Moment Closure for the Near-Wall Sublayer: Development and Application, AIAA J., 27(10), 1319-1325.

Murakami, M. and Kikuyama, K., 1980. Turbulent Flow in Axially Rotating Pipes, J. Fluids Engineering, 102, 97-103.

Nagano, Y. and Tagawa, M., 1988. Statistical Characteristics of Wall Turbulence with a Passive Scalar, J. Fluid Mech., 196, $157-185$.

Patankar, S.V., 1980. Numerical Heat Transfer and Fluid Flow, Hemisphere Publishing, Washington, DC.

Rehme, K., 1974. Turbulent Flow in Smooth Concentric Annuli with Small Radius Ratios, J. Fluid Mech., 64, 263-287.

Sommer, T.P., So, R.M.C. and Lai, Y.G., 1992. A Near-Wall Two-equation Model for Turbulent Heat Fluxes, Int. J. Heat Mass Transfer, 35(12), 3375-3387.

Torii, S. and Yang, W.J., 1994. A Numerical Study on Turbulent Flow and Heat Transfer in Circular Couette Flows, Numerical Heat Transfer, Part A, 26, 231-336.

Torii, S. and Yang, W.J., 1995a. Numerical Prediction of FullyDeveloped Swirling Flows in an Rotating Pipe by Means of a Modified $k-\varepsilon$ Turbulence Model, Int. J. Numerical Methods for Heat \& Fluid Flow, 5(2), 175-183.

Torii, S. and Yang, W.J., 1995b. A Numerical Analysis on Flow and Heat Transfer in the Entrance Region of an Axially Rotating Pipe, Int. J. Rotating Machinery, 2(2), 123-129.

Youssef, M.S., Nagano, Y. and Tagawa, M., 1992. A Twoequation Heat Transfer Model for Predicting Turbulent Thermal Fields under Arbitrary Wall Thermal Conditions, Int. J. Heat Mass Transfer, 35(11), 3095-3104. 


\section{ait \\ ENERGY MATERIALS}

M A N E Y publishing



\section{Materials Science \& Engineering for Energy Systems}

Maney Publishing on behalf of the Institute of Materials, Minerals and Mining

The Institute of Materials, Minerals \& Mining

Economic and environmental factors are creating ever greater pressures for the efficient generation, transmission and use of energy. Materials developments are crucial to progress in all these areas: to innovation in design; to extending lifetime and maintenance intervals; and to successful operation in more demanding environments. Drawing together the broad community with interests in these areas, Energy Materials addresses materials needs in future energy generation, transmission, utilisation, conservation and storage. The journal covers thermal generation and gas turbines; renewable power (wind, wave, tidal, hydro, solar and geothermal); fuel cells (low and high temperature); materials issues relevant to biomass and biotechnology; nuclear power generation (fission and fusion); hydrogen generation and storage in the context of the 'hydrogen economy'; and the transmission and storage of the energy produced.

As well as publishing high-quality peer-reviewed research, Energy Materials promotes discussion of issues common to all sectors, through commissioned reviews and commentaries. The journal includes coverage of energy economics and policy, and broader social issues, since the political and legislative context influence research and investment decisions.

\section{CALL FOR PAPERS}

Contributions to the journal should be submitted online at http://ema.edmgr.com

To view the Notes for Contributors please visit: www.maney.co.uk/journals/notes/ema

Upon publication in 2006, this journal will be available via the Ingenta Connect journals service. To view free sample content online visit: www.ingentaconnect.com/content/maney

For further information please contact:

Maney Publishing UK

Tel: +44 (0)113 2497481 Fax: +44 (0)1132486983 Email: subscriptions@maney.co.uk

or

Maney Publishing North America

Tel (toll free): 8662975154 Fax: 6173546875 Email: maney@maneyusa.com



EDITORS

Dr Fujio Abe

NIMS, Japan

Dr John Hald, IPL-MPT, Technical University of Denmark, Denmark

Dr R Viswanathan, EPRI, USA

\section{SUBSCRIPTION INFORMATION}

Volume 1 (2006), 4 issues per year

Print ISSN: 1748-9237 Online ISSN: 1748-9245

Individual rate: $£ 76.00 / U S \$ 141.00$

Institutional rate: $£ 235.00 /$ US $\$ 435.00$

Online-only institutional rate: $£ 199.00 / U S \$ 367.00$

For special $\mathrm{IOM}^{3}$ member rates please email

subscriptions@maney.co.uk

\section{For further information or to subscribe online please visit www.maney.co.uk}



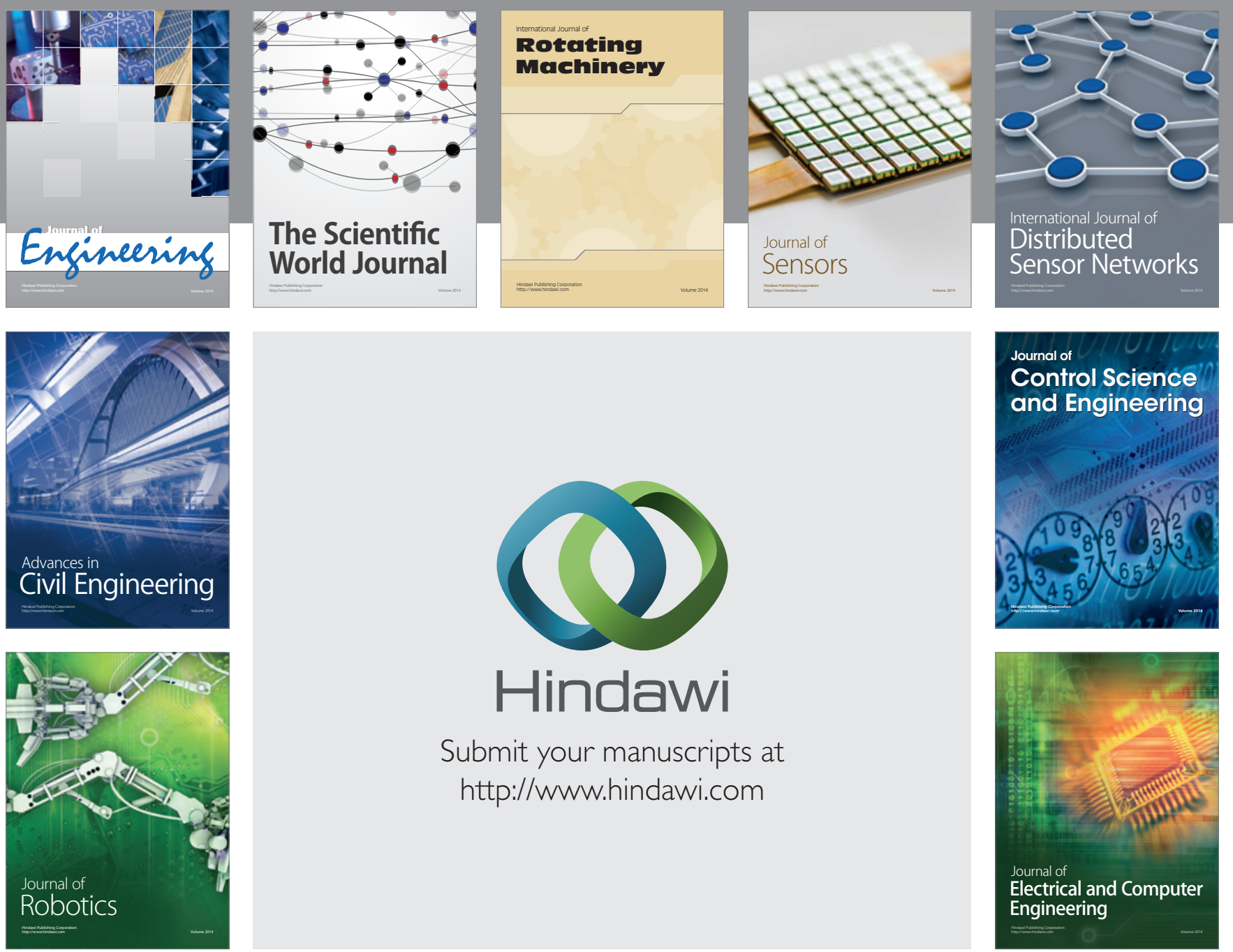

Submit your manuscripts at

http://www.hindawi.com
